\title{
OneUp: Supporting Practical and Experimental Gamification of Learning
}

\author{
Darina Dicheva ${ }^{1}$, Keith Irwin ${ }^{1}$, Christo Dichev ${ }^{1}$ \\ ${ }^{l}$ Winston-Salem State University \\ \{dichevad,irwink,dichevc\}@wssu.edu
}

\begin{abstract}
Gamification of education is still evolving. It lacks systematic studies assessing its effect in different learning contexts. Creating gamified courses is still difficult, since there is a lack of sufficient understanding of how to gamify learning and appropriate software support is missing. As a response to these challenges, we developed OneUp - a customizable platform aimed at facilitating the process of gamifying academic courses and enabling contextual studies on educational gamification. In this paper we rationalize our approach to building OneUp and present the underlying principles and motivations guiding its design. We also describe the platform functionality which includes support for integrating game design elements in learning activities, creating dynamic problems, and visualizing student performance and progress. At the end, we present a usability study of the platform and the assessment results from an end user perspective.
\end{abstract}

Keywords: Gamification of Education, Motivation, Self-Determination Theory;

\section{$1 \quad$ Introduction}

The low performance and high drop-out rates in many academic disciplines is frequently attributed to lack of student engagement and motivation [1]. This suggests the need of employing methods that have the potential to motivate students and improve their learning experience. Gamification represents a promising framework for educational interventions that can lead to increased motivation and engagement of students. The primary aim of gamifying education is to stimulate student interest in learning by creating fun, meaningful, and engaging learning activities. Gamification of learning refers to the process of making learning experiences more engaging and game-like by using game design elements and gameful experiences.

The study of gamification in education is still relatively nascent and lacks systematic and large-scale attempts to assess its effect in different learning scenarios with different gamification strategies. Although the majority of reported studies have found experimentally more positive than negative effects of gamification on motivation $[2,3,4]$, its effectiveness for learning remains inconclusive due to limitations of study design and analysis strategies [5]. A substantial part of the research studies only analyze certain gamification aspects, often disconnected from the learning activities, where gamification is reduced to a layer of points, badges, and leaderboards, while motivational and playful factors are largely disregarded. Other studies, although reporting encouraging short-term results in using educational gamification, have not yet proven its effectiveness for longterm engagement [6].

Gamification faces a lack of empirical evidence not only on its effectiveness but also on practical methods for design and implementation [3]. There are no commonly accepted theoretical frameworks or general principles on how to apply gamification strategies to specific learning situations. One reason for this is that most of the educational gamification 
pag. 6

studies use dissimilar combinations of motivational affordances. This limits the potential conclusions about the relations of specific configurations of game elements to specific sets of learning activities and specific populations of learners. Another reason is that conducting such experiments involves considerable effort, which limits the number of studies that can be performed. Thus, the question of how different aspects of gamification actually affect different motivational outcomes has not been empirically addressed sufficiently till now.

Another major barrier that hinders the growth of gamified academic courses is the lack of appropriate tools to support course gamification. Course gamification is about motivating particular student behavior in the course through the use of game elements, such as instant feedback, freedom to fail, freedom of choice, leveling, progress indicators, badges, and leaderboards. Gamification fitting a specific course structure or activities aligned with the vision of the instructor can be very time-consuming and design-limited without the support of an adequate platform that allows customization.

All of the above indicates the importance of having customizable educational gamification platforms that enable contextual studies and practices. This motivated us to develop OneUp Learning - a holistic educational gamification platform aimed at facilitating the gamification of academic courses and fostering experimental research on gamifying learning. To the best of our knowledge, it is the first highly configurable platform for gamifying courses or other structured learning activities. Differently from the existing gamification platforms, OneUp allows instructors not only to select the game elements to be used but also to define rules specifying their behavior. In addition, the instructors can enable learners to turn on and off the selected game features in accordance with their own preferences. This enables the instructors to promote a desired learners' behavior.

The implementation of an effective educational gamification platform is difficult as it requires knowledge in several areas, such as motivational psychology and software development, complemented with understanding of game design. This difficulty is amplified by the lack of sufficient understanding of how to gamify learning and the limitations of gamification design. To address this gap, in this paper we present our approach to building OneUp along with the underlying principles and motivations guiding its design. The main contributions of the paper are as follows:

- Identifying the need of customizable gamification platforms.

- Identifying learning activities suitable for gamification.

- Describing the principles of gameful design in learning contexts.

- Describing and rationalizing the OneUp novel architecture and its functionality.

- Reporting the results of a usability study of the platform.

\section{Background and related work}

Gamification is a relatively new term that is used to denote the use of game elements and game-design techniques in non-gaming contexts [7] to engage users and encourage them to adopt specific behaviors, such as becoming loyal to a brand or raising health awareness. Gamification draws on the motivational qualities of games, which make them good behavior drivers and powerful learning tools. In educational contexts, gamification has shown improvement in productivity and participation $[8,9,10]$. However, some studies have also reported that no effects, positive or negative, have been found in durability [9], quantity [8], or quality [10] of contributions by students. In particular, the impact of educational gamification on motivation is inconclusive, as it is backed by some contradicting reports $[5,6,11,12]$. Providing that gamification is expected to drive motivation for achieving better learning outcomes, such results can ultimately question its effectiveness for educational purposes [13]. In terms of learning performance, contrasting evidence has also been reported [8]. Several studies examine different reasons that may account for such contradictory results including the type of evaluation items [14], the type of assessed learning outcomes [8], or the type of knowledge that learning actions convey 
[15]. This in turn suggests that the effectiveness of gamification is highly contextual and more research is required to determine the specific circumstances under which gamification yields learning benefits.

Gamification is often misunderstood as being largely about adding points, badges, or leaderboards $[2,3,16]$. However, it is much more than a reward or ranking system - it is about applying elements of game design and principles of game-playing to non-game contexts. Lieberoth [17] introduces the terms "shallow gamification" and "deep gamification" to differentiate between relying on surface features and a few game elements and integrating intrinsic properties of the target behavior in the gameplay. While several studies have shown that the implementation of points, badges, and leaderboards may promote user behavior in various contexts, some have cautioned that they may diminish users' intrinsic interest $[2,3,7]$. In fact, previous psychological research provides sufficient evidence that certain forms of rewards, feedback, and other external events can have detrimental effects on intrinsic motivation [18] and a recent study suggests that the same may hold true for gamification [6]. On the other hand, it has been argued that a wellthought-out implementation of game elements may improve intrinsic motivation by satisfying users' innate psychological needs for autonomy, competence, and relatedness $[19,20]$. A related concept is gameful design [21], which refers to creating a more gamelike experience, sharing similarity with deep gamification as demonstrated in [22]. According to Deterding [7], gameful design and "gamification" frame the same extension of phenomena but through different intentional properties - as the design strategy of using game design elements (gamification) or the design goal of designing for gamefulness (gameful design).

The most prevalent theoretical framework applied to gamification is the SelfDetermination Theory of human motivation (SDT) [23]. According to SDT, individuals choose to exert effort and persist in an activity according to a continuum of self-determined regulation. At one end is intrinsic motivation, which denotes the pursuit of an activity for the sake of the activity itself - because it is inherently interesting or enjoyable. At the other end is the lack of motivation and in between is the extrinsic motivation, which refers to behaviors carried out to attain outcomes unrelated to the activity itself, such as rewards, praise, or grades. Both extrinsic and intrinsic motivation promote performance gains [23], but only the latter has been associated with improved psychological well-being, enhanced creativity and learning outcomes. While some extrinsic rewards have been found to reduce intrinsic motivation, they do not invariably undermine it; their effects are mediated by a person's perception of these events as informational or controlling [23], which in turn determines how they influence the innate psychological needs. According to SDT, humans have three fundamental psychological needs: autonomy (the power to make their own choices), competence (ability to effectively perform the behavior), and relatedness (authentic social connections with others). Satisfaction of these three needs is essential for an individual's intrinsic motivation.

While efforts have been undertaken to link game design elements to the satisfaction of motivational needs $[16,20,24]$, to date only a few studies have attempted to experimentally investigate the effects of individual game elements on motivation and performance $[2,3$, $12]$. The majority of current gamification literature (with a few notable exceptions $[6,17$, $25,26])$ focuses on studying the effectiveness of game design elements in promoting certain behavioral outcomes, ignoring the underlying psychological mechanisms that may actually account for these effects. Studies isolating the motivational effects of game elements are rare. Sailer et al. [27] address the issue of how certain facets of gamification affect different motivational outcomes based on SDT, however, their study was in the realm of order picking and they used simulation, which can only represent certain aspects of reality. Peng et al. [24] compared versions of an exergame, designed with various autonomy-supportive and competence-supportive game features. They found that need satisfaction mediated the effects of game elements on participants' motivation. Taking motivational theories, such as SDT as a theoretical basis may benefit designers as they allow for more informed decisions 
pag. 8

on how and under what circumstances certain game elements should or should not be implemented [16].

The identified gaps in educational gamification research and practice indicate the need for customizable gamification platforms that simplify the process of gamifying learning and enable contextual studies. However, the available support for gamifying learning activities is very limited. There are some general platforms, such as Badgeville [28], Bunchball [29], GamEffective [30], Gametize [31], Hoopla [32], and PugPharm [33], but their typical approach is to pack-in selected gamification techniques in 'one size fits all' systems, so that they would respond to the needs of enterprises with varying organizational structures. Education and learning in particular involves activities different from those in the corporate world, which entails the need of dedicated platforms. There are several gamification platforms targeting education, such as ClassCraft [34], Kahoot [35], Rezzly [36], Seppo [37], Youtopia [38], and ClassDojo [39]. However, although the developers of these platforms claim that they are suitable for all academic levels, they are designed with K-12 education in mind, where the focus is on class management and reward systems. An exception is Gradecraft [40], a system that applies gamification principles for tracking, predicting, and rewarding students' progress and provides learners with choices in selecting paths through a course. With a focus on learning analytics, it lacks a game engine for defining and driving gamified activities and the assortment of gamification elements used is limited. Some Learning Management Systems (e.g. Moodle) also offer certain gamification elements, however, they are limited in both the assortment of the offered elements (typically not configurable) and the possible scenarios that can be gamified. In addition, the instructors can only select their use for the entire class and without the ability to define the game elements' behavior.

The main difference of OneUp from other gamification platforms is that it is highly configurable and allows tailoring the gamification features to meet the vision of the course instructor and the preferences of the students, as well as conducting empirical studies for evaluating the effect of using different game elements and combinations thereof in different learning contexts.

\section{Designing gamification for gameful experiences}

The evidence from educational and psychological research suggests that humans are naturally driven to learn. While this fact is often in contradiction with the learning experience observed in formal education institutions, learning itself is an immense source of pleasure in games. The root of this contradiction lies in the fact that good games are systems purpose-built to optimally afford motivation and enjoyment, whereas most systems of formal education are not [41]. The joy and thrill in games comes from the feeling of competence, control, mastery, and self-efficacy in overcoming the game challenges [42, 43]. Thus, one critical factor of gaming motivation, which is insufficiently addressed in formal education, is the basic psychological needs for autonomy, competence, and relatedness and one central component of gaming enjoyment is the experience of having these needs satisfied [21]. The parallel between formal education and games also suggests that the activities which allow for autonomy, competence, and relatedness in their learning context are most compatible with the motivational qualities of games.

In line with SDT, gamified systems that support the fundamental psychological needs can be expected to increase students' intrinsic motivation, thus leading to efficient selfdetermined learning. However, simple combining of gamification strategies related to the three innate needs is not sufficient. For example, while visualization of social status and reputation (relatedness) may appeal to some students, it might be undesirable to others and conflict with their need for autonomy. Therefore, the most important design decision for OneUp, influenced by SDT, was to include gamification strategies supporting each of the three innate psychological needs, while developing a highly configurable platform that 
allows each gamification feature to be turned on and off to meet the individual preferences of both instructors and students. This design also allows empirical studies on the motivational aspects of different single game elements and combinations thereof.

\subsection{Gameful design}

Analysis of the existing gamification applications indicates that part of the problems in the current gamifying approaches arise from the narrow interpretation of the concept of game design element. Many authors inaccurately equate the motivational pull of games to achievements, rewards, and progress information that can be presented with points, badges, and leaderboards [4]. This somewhat downgrades gamification to interface look-and-feel driven by point systems. The assumption that simply adding elements found in games to learning activities will result in motivated actions like those observed in games is not confirmed by empirical studies [5].

Gameful design emerged as an alternative to gamification inspired by the idea of translating motivational qualities of games into a non-game interaction. Conceptually, gameful design is defined as affording game-like (gameful) experiences in any nongame context [7]. While in gamification (according to the popular interpretation of this concept) the focus is more on game elements used to address a goal, in gameful design the targeted game-like experience determines the means (game elements) to create it. When the target is to create intrinsically motivating learning experiences, gameful design is a more promising design approach. Instead of decorating the interactive environment with progress and achievement game elements, a gameful design strategy suggests the targeted learning activity to be framed in such a way that learners experience it as "game-like". Thus gameful design aims at deep gamification. A possible strategy to achieve gamefulness is to incorporate it into an environment that evokes a sense of autonomy, competence, and curiosity and that is driven by interaction/feedback cycles resulting from learner's actions.

Obviously, not all learning activities are amenable to gameful design. Required reading through a dry and complex textbook would be difficult to transform into an activity producing a game-like experience. Skill-related activities, on the other hand, are more amenable to gameful design. For example, if we are able to restructure skill learning activities into an interactive, challenging, and fun environment in which learners acquire the targeted skills, it could increase their drive to tackle the challenges and earn recognition for their achievements. The intended game-like experience here is suggested by analogous patterns in games. Playing games constitutes a model with constant deliberate practice, where there is a clear objective and rules, and where the observed feedback guides the next round of actions. A game needs to be easy enough to start playing but difficult enough to be interesting. This explains why most games are arranged around discrete tasks, a series of levels, and a long-term objective [7]. Such parallels between gaming and learning is instructive from the viewpoint of gameful design.

\subsection{Gameful practicing}

Game designers generally agree that game challenges are crucial in the design of gameplay experiences [21]. They evoke motivating experiences through multiple pathways. Overcoming non-trivial challenges creates the experience of competence need satisfaction [44]. Next, by deciding to approach a game challenge and choosing which challenges to approach with what strategies and actions, players perceive themselves as acting selfdeterminedly, satisfying their need for autonomy. Furthermore, the outcome of a non-trivial challenge is implicitly uncertain, stimulating motivational processes of curiosity and interest $[45,46]$.

In a learning context, exercise problems are analogous to game challenges. First, a learner chooses voluntarily whether to attempt exercise problems, which problems to approach, and how many to solve. Second, solving a problem successfully engenders a sense of competence. Continuing the analogy with games, a gameful environment for 
mastering skills should offer a platform for deliberate practice that provides multiple opportunities for demonstrating competence and receiving feedback in a risk-free environment. Creating and structuring learning exercises that make the practice interesting and engaging is at the heart of designing motivating experiences. Deciding on the nature and level of challenges is also important. Learning should be structured in carefully planned increments using meaningful challenges in order to increase engagement. This should break up the goal into many smaller sub-goals, allowing students to focus on the next step in the series and get immediate feedback as they complete each problem.

In order to approximate the repetitive pattern of game play featuring instant feedback and freedom to fail that allows players to master their game skills, the OneUp design requirements included support for online practicing with assessment, where the counterpart of game challenges are exercise problems with automatic checking. This is also in line with the value of deliberate practice for mastering particular skills. Encouraging students to practice, especially in sciences and mathematics, requires a rich pool of problems of different levels of difficulty. Having various levels of difficulty is essential, since students are more likely to be motivated by the feeling of flow [47], which is experienced when challenges match their individual skills, competences, and knowledge level. This led to a new design decision - providing support for dynamic generation of problems from templates. Offering dynamic problems with automated assessment enables evaluation that is impartial, consistent, and immediate. From a learning perspective, this moves students from a passive stance to an active position of tracking their own comprehension through an unconstrained pool of problems with immediate feedback.

\subsection{Rules}

What distinguishes a game from free-form play is having a goal and a set of rules which guide gamers' behavior in certain ways. Structuring a gameful learning environment thus requires rules that restrict and allow learners' actions and determine the effects thereof. The gameful experience is formed by the connection between the rules and the "game" they shape [48]. This implies a need for the gamification platform to enable instructors to set up and adjust 'the rules of the game', which will allow them to explore how different game rules influence learners' gameful experiences, so as to achieve improved motivation and engagement in their specific educational context. That need motivated our design decision for OneUp to enable instructors to set goals and define rules specifying the learners' actions and resulting effects. This ability is another fundamental aspect that distinguishes OneUp from other platforms, where software developers decide on the rules and hard code them in the system.

Exercise problems are probably as old as education itself. But, in general, they have not been considered as a gameful activity. The missing part is the game rules. The rules along with the challenges define the game-like experience. While practicing can be meaningful without rules, it would not be perceived as a game-like activity without appropriate rules. Rules are what can make an experience game-like, interesting, and intriguing. Having a particular set of exercise problems, by applying appropriate rules we can create different gameful experiences. The corresponding set of rules should be derived from the goal for gamifying the targeted learning activity, the potential motivational factors, and the game design elements at our disposal. The guiding principle for rule definitions is to trigger events that can increase the level of (possibly intrinsic) motivators or decrease the level of some potential de-motivators.

\subsection{Skill development}

Another inspiration from games impacting the design of OneUp was to provide a supportive environment for developing particular skills. Most games are skill-driven, involving skill development, challenges, and incremental progress. On the other hand, in an educational context not all topics are valued equally by the learners. This suggested designing 
mechanisms for mapping skills to selected exercise problems. This not only enables students to demonstrate and enjoy the mastery and get recognition for skills they value most, but also fosters their autonomy by allowing them to focus on developing those skills.

\subsection{Analytics and visualization}

In video games, feedback is half of the "circular model of gameplay" [49], where the gamer's input and the game's output reciprocally influence each other. Similarly, learners need to be able to track their progress toward the goal attainment, so that they can adjust their strategy and effort accordingly. That's why feedback, which is in the heart of the goal setting theory [50], is also a key element in most gameful design methods (e.g. [21, 51]). The related design requirement for OneUp was to produce instructive feedback by combining gamification with data analytics and visualization, so as to empower learners and teachers to make informed decisions about the learning process. The idea for the visualization tool was to be both informative and motivating by reflecting the student's skills, achievements, and learning growth and by providing intuitive visual insights for evaluating their progress and determining how to boost their results.

\section{A platform for gamifying academic courses}

We incorporated the design principles that we discussed above in the development of the OneUp Learning platform [52]. OneUp supports gameful redesign of academic courses, particularly courses that are focused on skill development. It enables instructors to define course activities and create exercise problems for practicing and self-assessment, as well as exams or quizzes for testing particular skills. All learning activities, such as practicing, completing quizzes, and participating in specified course activities, are provided with immediate feedback including detailed progress information and possibly some kind of reward (e.g. points, badges, virtual currency). All elements of the framework - the targeted skills, the learning content, the activities, the quizzes, the game design elements and the relations between them are configurable, which makes OneUp a course independent and customizable platform. This also allows empirical studies on the effectiveness of various combinations of game elements.

The adopted vocabulary reflects the game terminology: learning objectives are skills, tests and quizzes are challenges, and the questions in them are problems. Since freedom to fail and instant feedback are among the fundamental game design principles, special attention is given to supporting online practice with automatic assessment. To ensure a sufficient pool of exercises of a particular type for the students to practice, OneUp supports dynamic generation of problem instances from templates, which implies enabling instructors to easily create such templates. Thus the OneUp platform functionality includes: (1) support for the instructors to integrate game design principles and mechanics in their courses; (2) creating and checking static and dynamic problems, and (3) learning analytics and visualization to inform students and instructors of the student performance and progress throughout the course.

\subsection{OneUp functional model}

The functional model of the OneUp platform includes: Authoring tool, Configuration tool, Gamification engine, Challenge tool, Learner modeling tool, and Visualization tool [52]. As with any other course support system, the instructors have to configure their courses. The creation of a new course includes specifying the course topical structure, the learning objectives (skills) targeted in the course, the milestones and activities planned for the course (with their corresponding points), as well as game elements and gaming rules to be used in the course. The gaming rules define the conditions upon which certain game elements are 
applied (e.g. a badge is awarded). The instructor has also to enter problems and challenges. The platform supports two types of challenges: warm-up challenges (for student practice and self-assessment) and serious challenges (graded course quizzes and tests). When defining a challenge, instructors can choose from problems available in OneUp's problem bank or create new ones. For each problem included in the challenge, they specify the challenge points earnable from that problem, i.e., the problem's points in the context of the specific challenge. In this aspect, OneUp has pretty much the standard functionality of a Learning Management System. However, the instructor here also specifies how the problems contribute to increasing the level of student mastery of each related course skill.

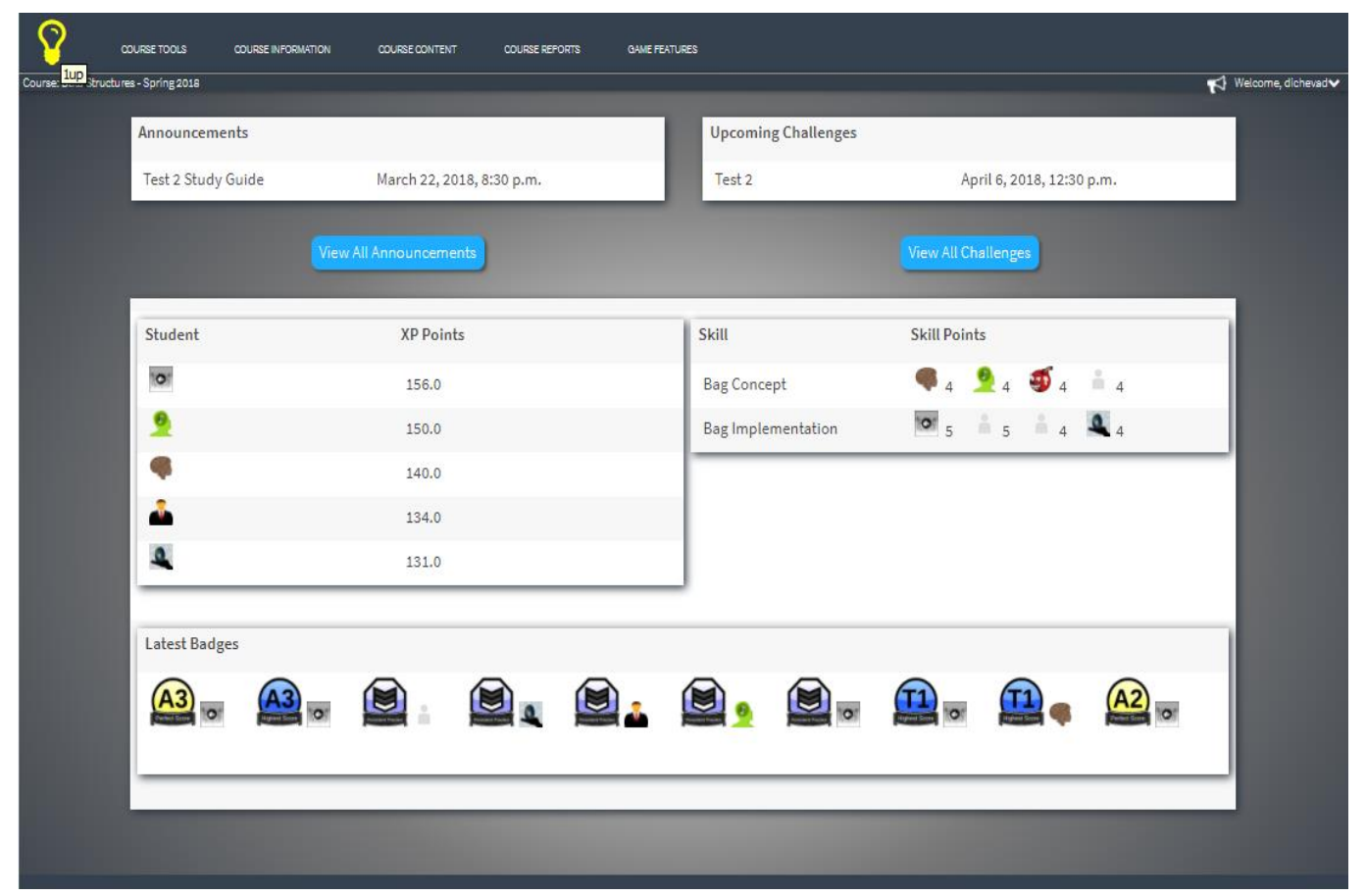

Figure 1. OneUp: Course Home.

The instructors configure their courses and enter instructional content using Configuration and Authoring tools. The Challenge tool delivers and scores challenges. The Learner tracking tool collects and processes student transaction logs, providing data for the assessment of student engagement. The Challenge and Learner tracking tools, as well as the Gamification rule engine feed student performance data to the Learning modeling tool, which updates the learner model. The latter is used by the Visualization tool to display the learner's progress and achievements on the student dashboard. This dashboard summarizes all aspects of students' performance: completed warm-up and serious challenges, skills, awarded badges, virtual currency earned, and progress towards meeting the course milestones. Fig. 1 presents the student course home page featuring the class leaderboard, and Fig. 2 presents the student dashboard.

\subsection{Dynamic problems}

OneUp challenges consist of problems which are static and/or dynamic and are scored automatically. Static problems are problems for which the correct solution is given at the time of entering them in the system. These include multiple choice questions, multiple answer questions, true/false questions, fill-in-the-blank questions, and matching questions. Problems for which the system does not contain 'canned' solutions entered by the instructor we call dynamic. These problems are short computer programs, which use a random seed 
to generate a unique instance of a particular programming or calculating problem and then grade the correctness of the answer submitted for that problem.

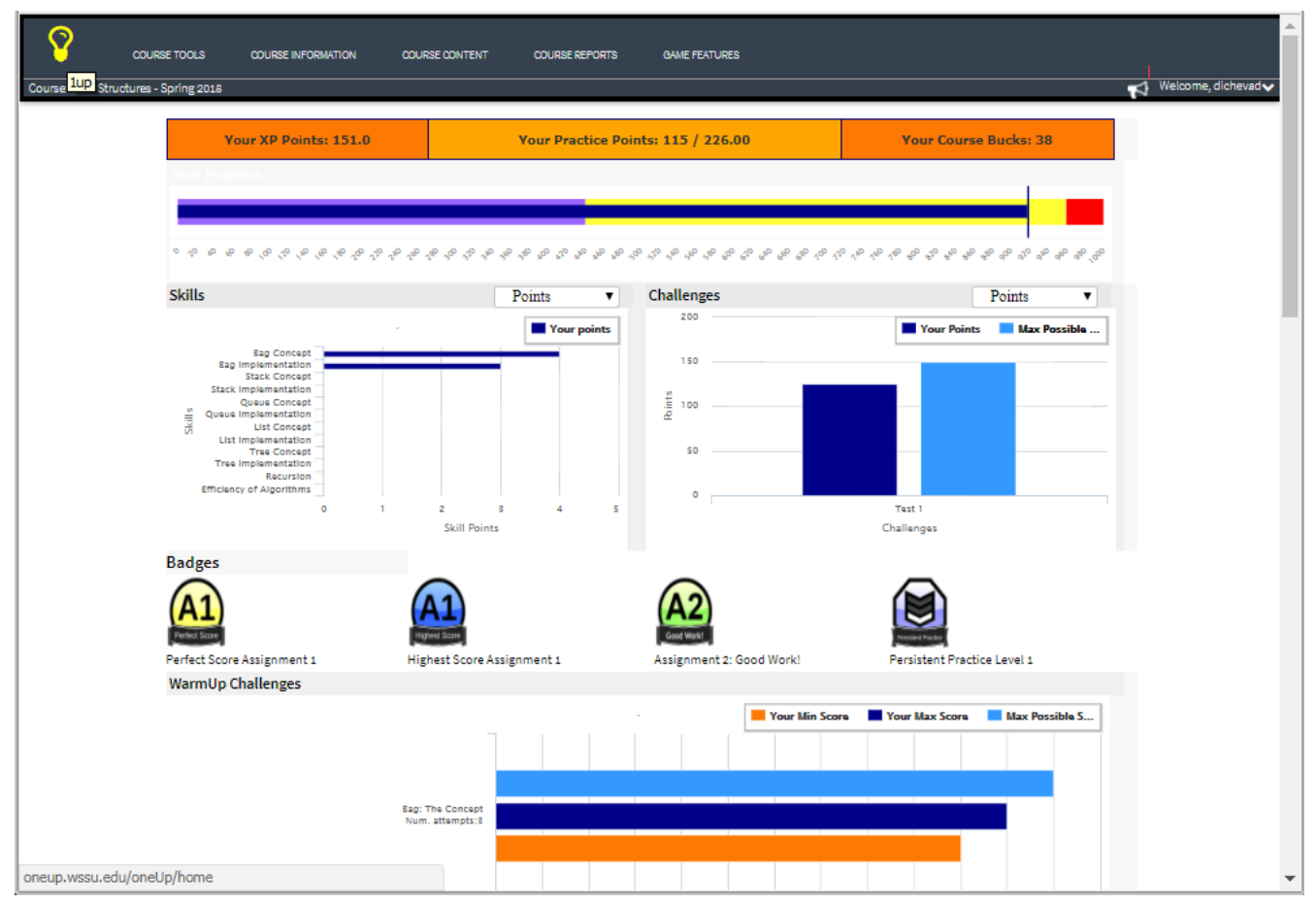

Figure 2. OneUp: Student Dashboard.

The platform supports two types of dynamic problems: (1) Programming problems for which students enter a solution in the form of program code and the system automatically checks its correctness by running the student's code through an independent problem solver, such as a compiler. For these problems, the instructor has to write the problem definition and provide testing code. (2) Problems that are dynamically generated as instances of parameterized templates. These templates allow the system to generate multiple non-identical instances of a problem and to check the correctness of the student solutions for them.

\subsection{Game elements supported by the platform}

We conducted an extensive review of the relevant literature $[4,5]$ to inform our choice of game mechanisms and selected the following:

- Points:

○ Skill points: points indicating the mastery of a specific skill targeted in the course.

- Challenge points: maximum possible points earned for completing a challenge (calculated using the points assigned to the challenge problems by the instructor).

- Activity points: points given by the instructor for participating in or performing a learning or class-related activity outside of the OneUp system. The instructor is able to define categories of learning activities, such as "attending events", "class presence", "participation in class discussions", etc., when configuring the course and to continuously add activities (with their description and points) to these categories during the semester.

Points can be used in game rules and are included in the aggregated information about student overall performance in the course. 
- Badges: the platform offers by default a chain of badges given for mastery of skills: "Novice", "Journeyman", and "Master". In addition, the instructor is able to define their own badges together with rules for receiving them. For example, "Perfect Score Badge" - for receiving a perfect score on a graded test, or "Perfect Monthly Class Attendance Badge". Other examples of conditions include: earning a specified number of points of a particular type; attempting a certain number of practice exercises; completing a challenge or learning activity within a certain time frame or with a score above a specified threshold. A user-friendly graphical interface enables easy defining of a badge with the rules for awarding it.

- Levels: leveling allows unlocking new problems and challenges based on performance (results from taking challenges, reached skill levels, etc.).

- Leaderboard: supports reputation, social credibility, and recognition.

- Avatars: by using avatars students can hide their identities and results.

- Virtual currency: the students are able to earn course 'bucks' and spend them for course-related benefits following rules defined by the instructor.

- Immediate feedback: apart from the instant reports of the results of taking challenges, the instructor can include encouraging messages.

- Freedom to fail: if a graded challenge is failed, a student may retake it upon certain conditions (defined by the instructor), e.g., after a certain amount of time, after successfully taking a certain number of practice challenges, etc.

The instructor selects the game elements that they want to incorporate in the organization of a specific course when creating and configuring the course in OneUp.

\subsection{Game engine and rules}

The platform's game engine is responsible for executing the rules, which are configured by the instructor. It is event-based and able to fire a chain of rules. Currently we consider the following events: logging into the system, starting a challenge, finishing a challenge, and entering information for a learning activity by the instructor.

The rules specify under what conditions (based on activities, challenges, and skills) specific game mechanisms will be applied. For example, a rule can specify that when all three challenges in a certain goal are completed, a certain badge will be given or some content will be unlocked for the student. All rules in the system have the format of a standard production rule:

IF < condition > THEN < action>.

Here are some examples of rules:

- "IF a challenge is completed THEN add the appropriate skill points to the skills targeted by the challenge problems."

- "IF a new warm-up challenge is completed with a score > 70\% THEN give the student 1 course buck."

- "IF the threshold for a skill badge is reached THEN present the badge to the student."

- "IF a challenge is marked as "difficult" and the score is $20 \%$ better than the previous taken challenge THEN congratulate the student", etc.

When certain game mechanisms are selected for a course, some rules will be automatically added for that course. The standard format of the rules allowed building an interface for the instructor to define additional rules by using rule templates and selecting choices (see Fig. 3). Examples of choices are options for using certain rules in the specific course, or numerical values presenting point thresholds, number of attempts, and the like 
which should be entered in the selected rules' templates. Default rules and values are included to help the instructor in their course configuration.

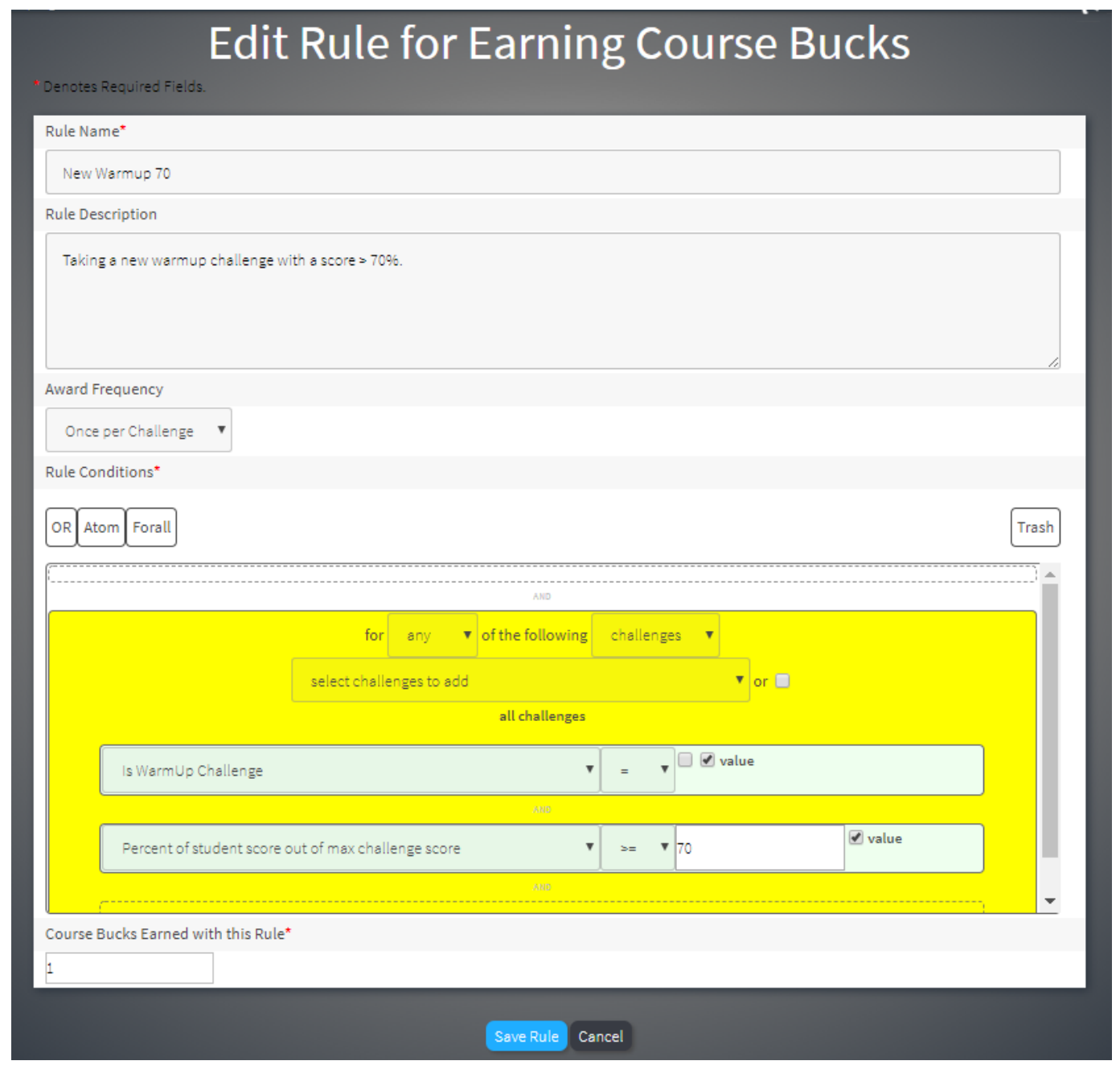

Figure 3. OneUp: Rule Interface.

OneUp rules provide instructors with a powerful instrument for driving desired behaviours in a predictive way. With different sets of rules, instructors can stimulate different behaviours, for example, motivating students to solve more problems, to solve different types of problems, to practice more frequently, to develop particular skills, etc.

The course gamification platform can support the gamification of different courses: each course will have its own set of configuration parameters, rules, and collection of challenges.

OneUp is implemented in Python using Django, a Model-View-Controller (MVC) Python Web Framework with a PostgreSQL database. Dynamic problems are implemented in Lua. The interface is in HTML5 and JavaScript, allowing the use of OneUp from mobile devices. The platform is currently in pilot use and evaluation. It has been used for gamifuying a Data Structures course in Spring 2018.

\section{$5 \quad$ OneUp usability study}

From the point of view of the end users of an interactive software system, usability is the most important aspect of the system. In terms of gamifying learning activities, Dominguez 
et al. conclude that a good usability testing process is essential when developing a gamification system, otherwise its motivational effects can be dramatically diminished by unaddressed usability and technical issues [14]. Similarly, addressing usability will eliminate cases where the tool fails to engage students because of poor usability which can cause none of the desired effects to be achieved. This is even more relevant for general platforms such as OneUp, which are intended for a wide variety of users. If the level of usage of a gamification platform is low because of poor usability, the effect of its engaging elements could be marginalized. Usability testing is particularly important when studying the motivating mechanisms of gamification and measuring the pure effect of gamification, where disruptive factors such as poor usability of the gamification platform should be minimized.

This section presents the results of usability testing of OneUp that was conducted, using the Software Usability Measurement Inventory (SUMI) [53]. We chose SUMI because it has been extensively validated with a standardization database of software systems with a long track record of success in the commercial market and in university courses.

\subsection{The study}

Participants. Fifteen participants took part in the anonymous study. (Note that SUMI gives reliable results with as few as 10 users [53].) The subjects were a mixture of different types of OneUp end users - students (7), instructors (6), and learning technology specialists (2).

The procedure. The study participants were informed about the purpose of the study and given instructions, consisting of three parts. In the first part, the participants were asked to $\log$ into the OneUp platform and complete thirteen typical tasks covering different aspects of the platform usage. Students and instructors were given different tasks, specific to the corresponding user group. Examples of instructors' tasks include creating a serious challenge containing two problems typical for their course (of different types) and configuring the gamification features for the class. Examples of student tasks include taking two warm-up challenges and buying something from the virtual currency course store. In the second part, the participants were asked to complete the SUMI questionnaire. In the third part, they were asked to answer some questions about OneUp aesthetics. The questionnaires were completed anonymously and no additional help was offered.

The SUMI instrument is comprised of 50 questions, in which respondents score each item on a three-point scale (agree, undecided, disagree). SUMI processes them and benchmarks the results to its standardization database, which is developed from commercial products and contains more than 1,000 cases. Standard scores in SUMI are expressed in a scale where the average is 50 and the standard deviation is 10. Two thirds of all SUMI standard scores are in the range 40 to 60 . Accordingly, the SUMI profiles and analysis of OneUp presented below are computed by using the SUMI mean value 50 and standard deviation 10. A SUMI score is reported for 5 subscales of usability (five different aspects of user satisfaction): Affect is the user's general emotional reaction to the software. Helpfulness is the degree to which the software is self-explanatory, as well as the adequacy of help facilities. Control measures how much the user feels in control of the navigation through the system. Learnability measures the facility of mastering the system, that is, how easy it is to learn how to use it. Global Usability is a composite measure of usability that describes the user's generalized perceived quality of use.

\subsection{Results of the study}

SUMI assesses the five aspects of user satisfaction and also includes a global satisfaction scale. Table 1 shows that OneUp has high ratings in all aspects, including the global score. Usability scores for efficiency, affect, control, learnability, and global score are all above or close to 60 . Note that a score of 60 is higher than about $85 \%$ of the scores in the samples in the SUMI standardized database, thus indicates relatively high user satisfaction. In 
contrast, a score of 40 is higher than only about $15 \%$ of the scores in the normative samples and suggests user dissatisfaction. Learnability received the highest mean score, which suggests that for the participants it was relatively easy to pick up how to use the platform. Although the score for helpfulness is lower than the remaining scores, it is still above the standardized average.

Table 1. SUMI results of the six scales.

\begin{tabular}{|l|r|r|r||r|c|}
\hline & Mean & St Dev & Median & Minimum & Maximum \\
\hline \hline Global & 58.40 & 10.38 & 61.0 & 34 & 70 \\
\hline \hline Efficiency & 60.53 & 12.01 & 67.0 & 37 & 74 \\
\hline \hline Affect & 62.07 & 12.16 & 68.0 & 36 & 74 \\
\hline \hline Helpfulness & 54.67 & 12.80 & 56.0 & 29 & 70 \\
\hline \hline Controllability & 58.73 & 10.48 & 60.0 & 42 & 74 \\
\hline \hline Learnability & 62.20 & 8.55 & 65.0 & 43 & 71 \\
\hline
\end{tabular}

The above usability results are promising. The tested interface was liked, and the respondents found it efficient, easy to learn, and felt in control. They did not find the platform so helpful, which reflects the fact that the help system has not been completed.

Fig. 4 below shows a closer perspective on the means for each of the SUMI scales and for the global usability scale. If the value for a scale is better than the reference database, then the bar is shown in green. The bars also show the range of the $95 \%$ confidence interval of the means using black vertical staples. The interpretation of staples: they show where the mean of the samples would fall $95 \%$ of the time if we repeat exactly the same survey with the same sample size, under identical conditions, on the same population of users for an infinite number of times. Specifically, the bars for effectiveness, affect, and helpfulness show a higher dispersion as a consequence of a higher disaccord in the scores among the relatively small number of participants.

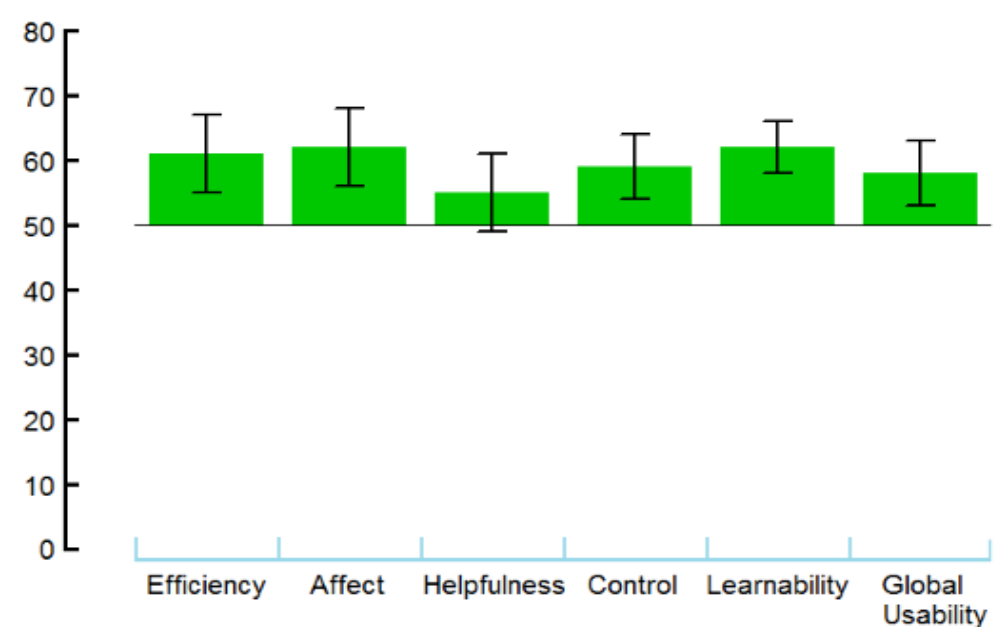

Figure 4. Mean profiles for the SUMI scales.

The SUMI report contains also a strength and weakness analysis and participant comments on a specific question relevant to the system usability. There were no statistically significant weaknesses of the tested interface in the SUMI report.

Answers to the question "What do you think is the best aspect of the platform, and why?" include: 
"The possibility for the instructor to configure whether they want to use particular game features. The visualization of dashboard elements, badges and achievements is eye catching."

"The leaderboard area is a neat feature. Being able to see how other students are faring in the same class is pretty cool."

"The ability to earn virtual currency is very engaging. Knowing that I can retake an assignment if I had virtual money sounds satisfying."

The aspects pointing to areas for possible improvements were revealed in some of the answers to the question "What do you think needs most improvement, and why?":

"Could add the ability to receive automated hints."

"It would be helpful if there was a quick 'how-to' tutorial section for each activity

listed on the home page."

"Make the alternatives (when present) in the form inputs more clear."

Since the completion of the usability study the platform has been expanded and enhanced taking into account the suggestions for possible improvements: the OneUp interface was redesigned and improved and the help system was completed and integrated into the system. Although one participant mentioned adding automated hints as a desirable improvement, providing a general, domain independent system, such as OneUp, with such capability is not feasible. It is impossible to generate automatically valuable hints without prior knowledge of the problem domain. OneUp supports hints manually entered by the instructor.

\section{Conclusion}

The goal of gamification is to provide learning experiences that are motivating, engaging, and effective. However, the lack of comprehensive understanding of the effects of gamification in learning contexts continues to inhibit educators from adopting effective gamification approaches. While gamification has been regarded as a promising learning technology approach, it has also been acknowledged that it is difficult to design and implement. As a result, gamification is often reduced to a system for collecting points with little connection to the activities that are being gamified. In addition, as the available support for a gameful design in a learning context is minimal, game-like motivational experiences are largely disregarded. All these challenges entail the need of a platform that can ease the creation of gamified learning activities and support experimental studies in the context of learning. The OneUp platform was created as a response to that need. It was designed with a twofold purpose: to facilitate the gamification of learning activities and to support experimental studies related to gamifying learning. It was developed as a highly configurable gamification platform whose design is founded on motivational theories and inspired by the ideas of improving students' gameful experiences. OneUp is aiming at learning activities that offer meaningful choices and foster a sense of autonomy, in particular, at activities that could be structured as a series of challenges with immediate feedback.

The success of any gamified platform is largely dependent on the user motivation and attitude. If a poorly designed interface makes users feel lost, confused, or frustrated, it will hinder its effective use. To evaluate the usability of the OneUp platform we performed a usability study by using the SUMI instrument. The results of the study, which was intended to provide both an assessment from an end user perspective and also diagnostic information for areas that need improvement, were positive.

Our future work will include a series of SDT-driven studies aimed at validating some results reported by previous experiments and demonstrating the impact of the SDT framework on the design of gamified learning activities. We intend also to explore how the 
less studied psychological needs of competence and relatedness can inform a gamification design.

Acknowledgments. This material is based upon work supported by the NSF project HRD 1623236 "Increasing Student Motivation and Engagement in STEM Courses through Gamification."

\section{References}

[1] Terrón-López, M.J., García-García, M.J., Velasco-Quintana, P.J., Gaya-López, M.C., \& Escribano-Otero, J.J., Design and Implementation of a Comprehensive Educational Model: Project Based Engineering School. International Journal of Engineering Pedagogy, 5(3), 53-60, 2015. https://doi.org/10.3991/ijep.v5i3.4673

[2] Hamari, J., Koivisto, J., \& Sarsa, H., "Does gamification work? - A literature review of empirical studies on gamification". In Proceedings of the 47th Hawaii International Conference on System Sciences, Hawaii, USA, 2014.

[3] Seaborn, K., \& Fels, D.I., Gamification in theory and action: a survey. International Journal of Human-Computer Studies, 74, 14-31, 2015. https://doi.org/10.1016/j.ijhcs.2014.09.006

[4] Dicheva, D., Dichev, C., Agre, G., \& Angelova, G., Gamification in Education: A Systematic Mapping Study. Educational Technology \& Society, 18(3), 75-88, 2015.

[5] Dichev, C., Dicheva, D., Gamifying education: what is known, what is believed and what remains uncertain: a critical review. International Journal of Educational Technology in Higher Education, 14:9, 2017. https://doi.org/10.1186/s41239-017-0042-5

[6] Hanus, M.D., \& Fox, J., Assessing the effects of gamification in the classroom: a longitudinal study on intrinsic motivation, social comparison, satisfaction, effort, and academic performance. Computers \& Education, 80, 152-161, 2015. https://doi.org/10.1016/j.compedu.2014.08.019

[7] Deterding, S., Dixon, D., Khaled, R., \& Nacke, L., "From game design elements to gamefulness: Defining "gamification". In Proceedings of the 15th international academic MindTrek conference envisioning future media environments, 9-15, Tampere, Finland, ACM, 2011. https://doi.org/10.1145/2181037.2181040

[8] Denny, P., "The effect of virtual achievements on student engagement". In Proceedings of the SIGCHI Conference on Human Factors in Computing Systems (CHI'13). New York, NY, USA: ACM, 2013. https://doi.org/10.1145/2470654.2470763

[9] Halan, S., Rossen, B., Cendan, J., \& Lok, B., High score! Motivation strategies for user participation in virtual human development. In J. Allbeck, N. Badler, T. Bickmore, C. Pelachaud, \& A. Safonova (Eds.), Intelligent virtual agents, 6356, 482-488. Springer Berlin Heidelberg, 2010.

[10] Li, W., Grossman, T., \& Fitzmaurice, G., "GamiCAD: A gamified tutorial system for first time autocad users". In Proceedings of the 25th annual ACM symposium on User Interface Software and Technology, Cambridge, Massachusetts, 2012.

[11] Hakulinen, L., Auvinen, T., \& Korhonen, A., "Empirical study on the effect of achievement badges in TRAKLA2 online learning environment". In Proceedings of the 2013 Learning and Teaching in Computing and Engineering, 2013. https://doi.org/10.1109/LaTiCE.2013.34

[12] Landers, R. N., \& Landers, A. K., An empirical test of the theory of gamified learning: the effect of leaderboards on Time-on-Task and academic performance. Simulation \& Gaming, 45(6), 769-785, 2014. https://doi.org/10.1177/1046878114563662

[13] Boticki, I., Baksa, J., Seow, P., \& Looi, C.-K., Usage of a mobile social learning platform with virtual badges in a primary school. Computers \& Education, 86, 120-136, 2015. https://doi.org/10.1016/j.compedu.2015.02.015

[14] Domínguez, A., Saenz-de Navarrete, J., de Marcos, L., Fernandez-Sanz, L., Pages, C., \& Martínez-Herraiz, J.J., Gamifying learning experiences: Practical implications and outcomes. Computers \& Education, 63(0), 380-392, 2013. https://doi.org/10.1016/j.compedu.2012.12.020

[15] de-Marcos, L., Garcia-Lopez, E., \& Garcia-Cabot, A., On the effectiveness of game-like and social approaches in learning: comparing educational gaming, gamification \& social networking. Computers \& Education, 95, 99-113, 2016. https://doi.org/10.1016/j.compedu.2015.12.008 
[16] Mekler, E.D., Brühlmann, F., Tuch, A.N., \& Opwis, K., Towards understanding the effects of individual gamification elements on intrinsic motivation and performance. Computers in Human Behavior, 71, 525-534, 2017. https://doi.org/10.1016/j.chb.2015.08.048

[17] Lieberoth, A., Shallow Gamification: Testing Psychological Effects of Framing an Activity as a Game, Games and Culture, 10(3), 229-248, 2015. https://doi.org/10.1177/1555412014559978

[18] Deci, E., Koestner, R., \& Deci, R., A meta-analytic review of experiments examining the effects of extrinsic rewards on intrinsic motivation. Psychological Bulletin, 125, 627-668, 1999. https://doi.org/10.1037/0033-2909.125.6.627

[19] Deterding, S., Eudaimonic design, or: six invitations to rethink gamification. In M. Fuchs, S. Fizek, P. Ruffino, \& N. Schrape (Eds.), Rethinking gamification, 305-331, Meson Press, 2014.

[20] Francisco-Aparicio, A., Gutierrez-Vela, F. L., Isla-Montes, J. L., \& Sanchez, J. L. G., Gamification: analysis and application. In New Trends in Interaction, Virtual Reality and Modeling, 113-126, Springer, 2013.

[21] Deterding S., The Lens of Intrinsic Skill Atoms: A Method for Gameful Design. HumanComputer Interaction, 30(3-4), 294-335, 2015. https://doi.org/10.1080/07370024.2014.993471

[22] Santos, P., "Deep Gamification of a University Course". In Proceedings of Sciences and Technologies of Interaction (SciTecIN'15), Coimbra, 2015.

[23] Ryan, R., \& Deci, E., Intrinsic and extrinsic motivations: classic definitions and new directions. $\begin{array}{llll}\text { Contemporary } & \text { Educational } & \text { Psychology, 25, }\end{array}$ https://doi.org/10.1006/ceps.1999.1020

[24] Peng, W., Lin, J., Pfeiffer, K., \& Winn, B., Need satisfaction supportive game features as motivational determinants: an experimental study of a Self Determination Theory guided $\begin{array}{lllll}\text { exergame. } & \text { Media } & \text { Psychology, } & 15, & 175-196,\end{array}$ https://doi.org/10.1080/15213269.2012.673850

[25] Mekler, E.D., Brühlmann, F., Opwis, K., \& Tuch, A.N., "Do points, levels and leaderboards harm intrinsic motivation?: An empirical analysis of common gamification elements". In Proceedings of the First International Conference on Gameful Design, Research, and Applications, 66-73, ACM, 2013.

[26] Hamari, J., Do badges increase user activity? A field experiment on the effects of gamification. Computers in Human Behavior, 71, 469-478, 2017. https://doi.org/10.1016/j.chb.2015.03.036

[27][27]Sailer, M., Hense, J.U., Mayr, S.K., \& Mandl, H., How gamification motivates: An experimental study of the effects of specific game design elements on psychological need satisfaction. Computers in Human Behavior, 69, 371-380, 2017. https://doi.org/10.1016/j.chb.2016.12.033

[28][28]Siu, A. "Badgeville Motivation Platform Gamifies the Workplace, CMS Wire, 2016. Retrieved from https://www.cmswire.com/social-business/badgeville-motivation-platformgamifies-the-workplace/

[29] "Bunchball Official Website," https://www.bunchball.com/

[30] "Gameffective Official Website," https://www.gameffective.com/

[31] "Gametize Official Website," https://gametize.com/index

[32] "Hoopla Official Website," https://www.hoopla.net/

[33] "Pugpharm Official Website," http://www.pugpharm.com/index.html\#!home

[34] Sanchez, E., Young, S., \& Jouneau-Sion, C., ClassCraft: from Gamification to Ludicization of Classroom Management, Education and Information Technologies, 5(20), 1-17, 2016.

[35] "Kahoot!," https://kahoot.com/welcomeback/

[36] "Rezzly Official Website," https://www.rezzly.com/

[37] "Seppo Official Website," http://seppo.io/en/

[38] Antle, A.N., Wise, A.F., Hall, A., Nowroozi, S., Tan, P., Warren, J., Eckersley, R., \& Fan, M., "Youtopia: a collaborative, tangible, multi-touch, sustainability learning activity". In Proceedings of the 12th International Conference on Interaction Design for Children Conference, ACM Press, 565-568, 2013.

[39] "ClassDojo" https://www.classdojo.com/

[40] Aguilar, S.J., Holman, C., \& Fishman, B. J., Game-Inspired Design: Empirical Evidence in Support of Gameful Learning Environments. Games and Culture, 1-27, 2015. https://doi.org/10.1177/1555412015600305

[41] Deterding, S., "Paidia as Paideia: From Game-Based Learning to a Life Well Played". Keynote. In GLS 8.0. Madison, Wisc., 2012. Retrieved from http://codingconduct.cc/Paideia-as-Paidia

[42] Rigby, S., \& Ryan, R., "The Player Experience of Need Satisfaction (PENS): An applied model and methodology for understanding key components of the player experience", 2007. Retrieved from ftp://ftp.immersyve.com/PENS_Sept07.pdf 
[43] Koster, R., Theory of Fun for Game Design. Paraglyph. Press, Scottsdale, 2005.

[44] Przybylski, A. K., Rigby, C. S., \& Ryan, R. M., A motivational model of video game engagement. Review of General Psychology, 14, 154-166, 2010. https://doi.org/10.1037/a0019440

[45] Malone, T., Toward a theory of intrinsically motivating instruction. Cognitive Science, 5, 333 369, 1981. https://doi.org/10.1207/s15516709 cog0504_2

[46] Silvia, P. J., Curiosity and motivation. In R. M. Ryan (Ed.), The Oxford handbook of human motivation, 157-167, Oxford University Press, 2012.

[47] Csikszentmihalyi, M., "The flow experience and its significance for human psychology", In M. Csikszentmihalyi \& I. S. Csikszentmihalyi (Eds.), Optimal experience: Psychological studies of flow in consciousness, 15-35, New York, NY: Cambridge University Press, 1988.

[48] Salen, K. \& Zimmerman, E., Rules of play: Game design fundamentals. MIT Press, 2004.

[49]Heaton, T., "A circular model of gameplay". Gamasutra.com, 2006. Retrieved from http://www.gamasutra.com/features/20060223/heaton 01.shtml

[50] Locke, E.A. \& Latham, G.P., Building a Practically Useful Theory of Goal Setting and Task Motivation: A 35-Year Odyssey, American Psychologist, 57 (9), 705-717, 2002. https://doi.org/10.1037/0003-066X.57.9.705

[51] Morschheuser, B., Werder, K., Hamari, J. \& Abe, J., "How to gamify? A method for designing gamification", In Proceedings of 50th Annual Hawaii International Conference on System Sciences (HICSS), IEEE, 2017.

[52] Dicheva, D., Irwin K., Dichev C., "OneUp Learning: A Course Gamification Platform". In the Proceedings of Games and Learning Alliance Conference (GALA 2017), Lisbon, Portugal, 2017.

[53] Kirakowski, J., Corbett, M., SUMI: The Software Usability Measurement Inventory, British Journal of Educational Technology, 24 (3), 210-212, 1993. https://doi.org/10.1111/j.14678535.1993.tb00076.x 